\title{
PRODUTIVIDADE E COMPOSIČ̃̃O BROMATOLÓGICA DO CAPIM-MARANDU A FONTES E DOSES DE NITROGÊNIO ${ }^{1}$
}

\author{
Yield and bromatologic composition of Marandu grass as function of sources and doses of nitrogen
}

\author{
Cleiton Gredson Sabin Benett ${ }^{2}$, Salatiér Buzetti ${ }^{3}$, Katiane Santiago Silva ${ }^{2}$, \\ Antônio Fernando Bergamaschine ${ }^{4}$, Juliano Alarcon Fabricio ${ }^{5}$
}

\begin{abstract}
RESUMO
Objetivou-se, no trabalho, avaliar o efeito de doses e fontes de nitrogênio nas características produtivas e qualitativas da Brachiaria brizantha cv. Marandu. O delineamento experimental utilizado foi o de blocos ao acaso, em esquema fatorial $5 \times 3 \times 3$ (5 doses de N, 3 fontes de nitrogênio e 3 cortes), com 4 repetições. As doses de $\mathrm{N}$ foram: 0, 50,100,150, $200 \mathrm{~kg} / \mathrm{ha} / \mathrm{corte}$, com as fontes: Entec - sulfonitrato de amônio + inibidor de nitrificação (dimetilpirazolfosfato), Sulfato de Amônio e Uréia, sendo os cortes realizados em novembro/2006, dezembro/2006 e janeiro/2007. As coletas foram realizadas com intervalos entre corte de 30,30 e 34 dias onde se determinou a produtividade de massa seca, teor de proteína bruta (PB), fibra em detergente neutro (FDN), fibra em detergente ácido (FDA), nutrientes digestíveis totais (NDT) e teor de clorofila. As leituras no clorofilômetro foram lineares crescentes quando se utilizaram o Entec e a Uréia, até $200 \mathrm{~kg} / \mathrm{ha}$ de $\mathrm{N}$ e, até $174 \mathrm{~kg} / \mathrm{ha}$ de N, com a utilização do Sulfato de amônio; apresentando correlação significativa com os teores de $\mathrm{N}$ na planta. Independente da fonte nitrogenada, a aplicação de doses crescentes de até 200 $\mathrm{kg}$ de N/ha/aplicação na forrageira Brachiaria brizantha cv. Marandu proporcionou incremento na produção de massa seca, melhorando a composição bromatológica por aumentar os teores de PB e NDT e, diminuição dos teores de FDN e FDA.
\end{abstract}

Termos para indexação: Adubação, Brachiaria brizantha, pastagens, produtividade de massa seca.

\section{ABSTRACT}

This study aimed to evaluate the effect of doses and sources of nitrogen in the productivity and quality characteristics of Brachiaria brizantha cv. Marandu. A randomized block design in a factorial scheme $5 \times 3 \times 3$, with 4 repetitions was used. The treatments were constituted by 5 doses of nitrogen: $0,50,100,150,200 \mathrm{~kg} / \mathrm{ha} / \mathrm{cut}, 3$ sources: Entec - amonium sulfonitrate + nitrification inhibitor - dymethilpirazolphosphate, Ammonium sulfate and Urea, in 3 cuts, accomplished with intervals of 30, 30 and 34 days to evaluate the production of dry mass, crude protein content (PB), neutral detergent fiber (NDF), acid detergent fiber (ADF), total digestible nutrients (NDT) and chlorophyll content. The chlorophilometer data increased when user as a function of $\mathrm{N}$ doses with Entec and Urea sources and up to $174 \mathrm{~kg} / \mathrm{ha}$ of $\mathrm{N}$ with ammonium sulfate; showing significant correlation with $\mathrm{N}$ content in plants. Independently of the source, the application up to $200 \mathrm{~kg} \mathrm{~N} / \mathrm{ha} /$ application in Brachiaria brizantha cv. Marandu provided increment in the production of dry mass improving the quality composition for increasing the PB and NDT content and, decreasing the FDN and FDA contents.

Index terms: Brachiaria brizantha, fertilization, pastures, production of dry mass.

(Recebido em 8 de janeiro de 2008 e aprovado em 17 de junho de 2008)

\section{INTRODUÇÃo}

O Brasil é o maior produtor comercial de bovinos do mundo, devido a vários fatores, especialmente os climáticos, que favorecem a produção de forragens nas diferentes localidades e períodos do ano. A atividade pecuária está sendo uma das principais atividades responsáveis pelo crescimento econômico do país.

As pastagens totalizam aproximadamente $25 \%$ da superfície terrestre, sendo que o Brasil possui mais de 200 milhões de hectares de pastagens, e a grande parte é constituída por pastagens naturais. A região dos Cerrados conta com cerca de 40 milhões de hectares cultivados com Braquiaria. As plantas forrageiras normalmente não recebem nenhum tipo de adubação e com o decorrer dos anos acabam perdendo o seu potencial de desenvolvimento, reduzindo a sua qualidade e produtividade. Assim, o uso de nitrogênio visa aumentar a recuperação do nitrogênio aplicado ao sistema solo-planta,

${ }^{1}$ Parte do trabalho de dissertação de mestrado do primeiro autor

2Engenheiros Agrônomos, Doutorandos em Agronomia - Faculdade de Engenharia de llha Solteira/FEIS - Universidade Estadual Paulista/UNESP - Rua Caruaru 95, Apto 14 - Zona Norte - 15385-000 - Ilha Solteira, SP - cbenett@hotmail.com; kasantiago@ig.com.br - Bolsista Capes

${ }^{3}$ Engenheiro Agrônomo, Doutor, Professor - Departamento de Fitossanidade, Engenharia Rural e Solos/DEFERS - Faculdade de Engenharia de Ilha

Solteira/FEIS - Universidade Estadual Paulista/UNESP - Rua Monção, 226 - Zona Norte - Cx. P. 31 - 15385-000 - sbuzetti@agr.feis.unesp.br

${ }^{4}$ Zootecnista, Doutor, Professor - Departamento de Biologia e Zootecnia - Faculdade de Engenharia de Ilha Solteira/FEIS - Universidade Estadual

Paulista/UNESP - Rua Monção, 226 - Zona Norte - Cx. P. 31 - 15385-000 - berga@bio.feis.unesp.br

${ }^{5}$ Engenheiro Agrônomo, Mestre em Agronomia - Sítio Rancho Alegre - 15275-000 - Monções, SP _ juliano_fabricio@yahoo.com.br 
minimizando as perdas do nitrogênio fertilizante, sem ocasionar efeitos danosos ao meio ambiente. $\mathrm{O}$ nitrogênio possui grande destaque na produção de massa seca, sendo um dos principais nutrientes a proporcionar maior perfilhamento e produção, melhorando a qualidade da forragem produzida e aumentando a capacidade de animais por área.

Fagundes et al. (2005) verificaram que o suprimento de $\mathrm{N}$ no solo, normalmente, não atende à demanda das gramíneas, porém, quando a adubação nitrogenada é realizada, observam-se grandes alterações na taxa de acúmulo de massa seca da forragem do capim-braquiária, ao longo das estações do ano. Ruggieri et al. (1995), ao avaliarem doses de nitrogênio e regimes de corte em Brachiaria brizantha, verificaram que, aos 28 dias de intervalo de corte, os valores de PB foram de 13,5; 16,3 e 17,3\% para as doses de nitrogênio de 0,33 e $66 \mathrm{~kg} / \mathrm{ha} /$ corte.

Alexandrino et al. (2005), estudando o crescimento e características químicas e morfogênicas do capimMarandu, verificaram grande diferença de perfilhamento ao longo do tempo de rebrotação, em relação ao suprimento de $\mathrm{N}$, observando que as plantas não adubadas com $\mathrm{N}$ pouco perfilharam, diminuindo a produtividade. Carvalho et al. (1991) avaliaram as respostas de gramíneas forrageiras à adubação nitrogenada e constataram incrementos marcantes na produção de massa seca da Brachiaria decumbens quando esta foi submetida a doses crescentes de $\mathrm{N}$ até a dose de $400 \mathrm{~kg} / \mathrm{ha} / \mathrm{ano}$.

Objetivou-se, no trabalho, avaliar o efeito de cinco doses de $\mathrm{N}(0,50,100,150$ e $200 \mathrm{~kg} / \mathrm{ha} /$ corte $)$ e três fontes de nitrogênio (Entec - sulfonitrato de amônio, com inibidor de nitrificação, Sulfato de amônio e Uréia), em três cortes, nas características produtivas e qualitativas da Brachiaria brizantha cv. Marandu.

\section{MATERIAL E MÉTODOS}

O experimento foi conduzido na Fazenda de Ensino, Pesquisa e Extensão da Universidade Estadual Paulista "Júlio de Mesquita Filho", Campus de Ilha Solteira - SP, localizado à margem esquerda do Rio Paraná, com coordenadas $20^{\circ} 21^{\prime}$ latitude sul e $51^{\circ} 22$ ' longitude oeste, a uma altitude de 326 metros. Os dados climáticos referentes ao período de condução do trabalho (meses de outubro/2006 a janeiro/ 2007) encontram-se na Figura 1. O solo foi classificado como Argissolo Vermelho Eutrófico, textura arenosa (EMBRAPA, 1999) com os seguintes atributos: $\mathrm{P}$ (resina) $=13 \mathrm{mg} / \mathrm{dm}^{3}$, $\mathrm{M} . \mathrm{O}=21 \mathrm{~g} / \mathrm{dm}^{3}, \mathrm{pH} \mathrm{CaCl}_{2}=5,2, \mathrm{~K}, \mathrm{Ca}, \mathrm{Mg}, \mathrm{H}+\mathrm{Al}=3,6,17,0$, 6,0 e $21,0 \mathrm{mmol} / \mathrm{dm}^{3}$, respectivamente.

O experimento foi instalado no início do mês de agosto de 2006, a área foi preparada com uma aração e duas gradagens onde se realizou a adubação básica de fósforo utilizando o superfosfato simples, tentando-se elevar o teor de P no solo a $40 \mathrm{mg} / \mathrm{dm}^{3}\left(124 \mathrm{~kg} / \mathrm{ha}\right.$ de $\left.\mathrm{P}_{2} \mathrm{O}_{5}\right)$. Após adubação foi realizada a semeadura, no dia 21 de agosto de 2006, da Brachiaria brizantha cv. Marandu.

$\mathrm{O}$ delineamento experimental foi o blocos ao acaso em esquema fatorial $5 \times 3 \times 3$, sendo, 5 doses de nitrogênio $(0,50,100,150,200 \mathrm{~kg} / \mathrm{ha} /$ corte $), 3$ fontes de nitrogênio (Entec - sulfonitrato de amônio, com inibidor da nitrificação, sulfato de amônio e uréia) e 3 cortes, com 4 repetições. Realizou-se a aplicação a lanço das diferentes doses e

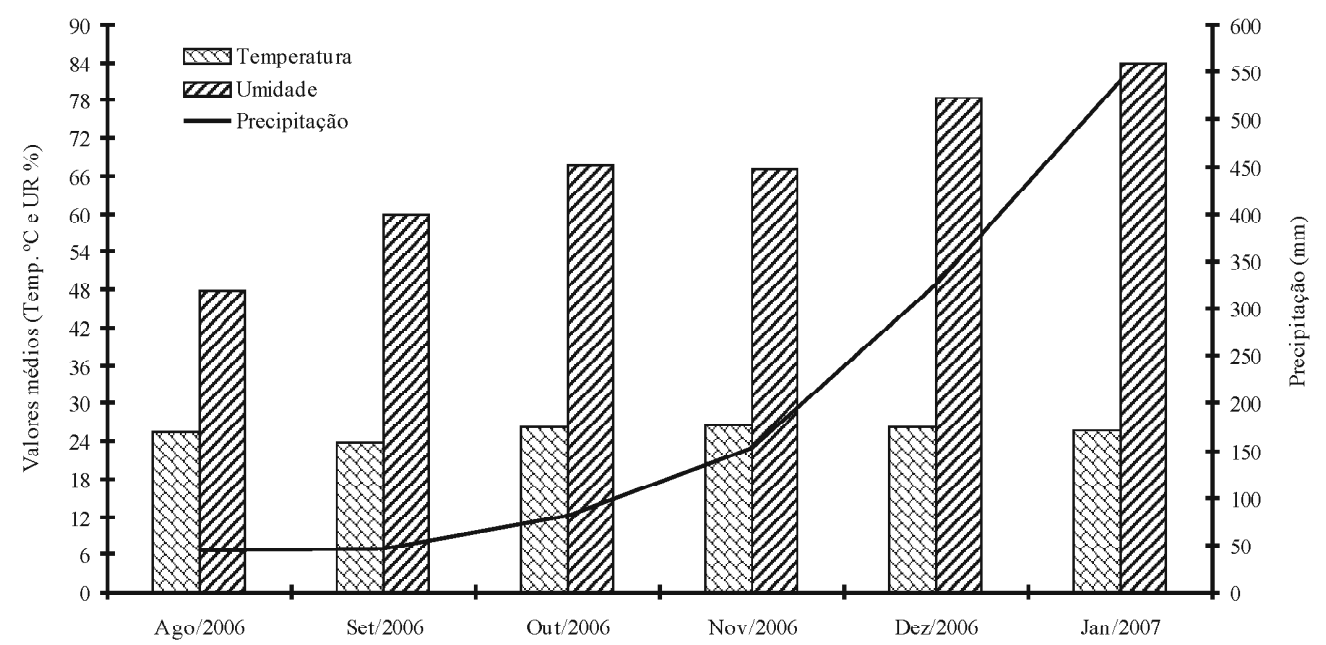

Figura 1 - Valores médios de temperatura $\left({ }^{\circ} \mathrm{C}\right)$, umidade relativa do ar $(\%)$ e precipitação $(\mathrm{mm})$, durante o período experimental. 
fontes de nitrogênio, e o corte de homogeneização após cada coleta de material. A área foi dividida em parcelas de $6 \mathrm{~m}^{2}$ nas quais foram distribuídos os tratamentos.

As coletas foram realizadas em 07/11/2006, 15/12/ 2006 e 10/01/2007 com intervalos de 30, 30 e 34 dias, respectivamente. As amostras foram obtidas através do corte do material existente dentro de um quadrado de ferro $100 \mathrm{~cm}$ x $100 \mathrm{~cm}$ arremessado, aleatoriamente, em cada área útil da parcela. Esse material foi ceifado a aproximadamente 20 a 25 $\mathrm{cm}$ do solo. Em seguida retiraram-se as amostras para determinação da massa verde e seca, sendo essa, realizada após a secagem das amostras em estufa de circulação de ar forçada, com temperatura a $65^{\circ} \mathrm{C}$ por 72 horas. Após a secagem, o material foi moído em moinho tipo Wiley equipado com peneira de malha com abertura de $1 \mathrm{~mm}$ para serem amostrados $2 \mathrm{~g}$ de massa seca e levado à estufa a $105^{\circ} \mathrm{C}$, por 12 horas para se quantificar a segunda massa seca.

Foram realizadas determinações de produção de massa seca (MS) e teores de proteína bruta (PB), fibra em detergente neutro (FDN), fibra em detergente ácido (FDA) utilizando metodologia descrita em Silva \& Queiroz (2002). A digestão para obtenção do FDN e FDA foi realizada em aparelho de digestão de fibra (Tecnal TE-149), similar ao Ankon. As amostras foram colocadas em saquinhos de tecido de TNT $80 \mathrm{~mm}$, com tamanho de $25 \mathrm{~cm}^{2}$, selados, sendo que em cada um foi dispensado $0,5 \mathrm{~g}$ de massa seca moída. Os valores de nutrientes digestíveis totais (NDT) foram estimados conforme Cappelle et al. (2001).

A leitura da clorofila foi realizada na posição do terço médio da lâmina foliar da segunda folha completamente expandida a partir do ápice de cada planta através de um clorofilômetro digital (SPAD), retirando-se 5 pontos de cada parcela.

Os dados foram submetidos à análise de variância (teste F) e as médias comparadas pelo teste Tukey, a 5\% de probabilidade, para fontes e épocas de corte. Para as doses de nitrogênio foram ajustadas análises de regressão. As análises estatísticas foram realizadas utilizando o Software SANEST.

\section{RESULTADOS E DISCUSSÃO}

Os dados referentes à produtividade de massa seca (MS) da Brachiaria brizantha cv. Marandu (kg/ha) revelaram efeito significativo, havendo interação em função das doses de nitrogênio e época de corte (Figura 2). No primeiro corte, pôde-se constatar, por meio da equação de regressão, aumento linear na produtividade de massa seca em função das doses de nitrogênio aplicadas. No segundo corte, os dados referentes à produtividade de massa seca, em função das doses de nitrogênio, se ajustaram a uma regressão quadrática com o ponto de máxima estimada em $179 \mathrm{~kg} / \mathrm{ha}$ de $\mathrm{N}$ ( $2.097 \mathrm{~kg} / \mathrm{ha}$ de MS). O mesmo ocorreu para o terceiro corte, porém, o ponto de máxima foi obtido com a dose de $141 \mathrm{~kg} / \mathrm{ha}$ de $\mathrm{N}(8.456 \mathrm{~kg} / \mathrm{ha}$ de MS $)$. Os resultados de produção são semelhantes aos de Dupas (2006) quando utilizou $200 \mathrm{~kg} / \mathrm{ha}$ de $\mathrm{N}$ no capim Brachiaria brizantha, no período da primavera, e aos de Fabricio (2007) no mesmo período com o capim-Tobiatã e superiores aos encontrados

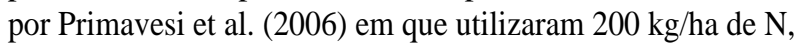
obtendo produtividade de $6.650 \mathrm{~kg} / \mathrm{ha}$ aos 45 dias para o capim Brachiaria brizantha.

Os teores de proteína bruta $(\mathrm{PB})$ revelaram efeito significativo para interação entre cortes e fontes nitrogenadas e para corte e doses de nitrogênio. Quando se analisou o desdobramento da interação entre cortes e fontes de nitrogênio (Tabela 1), no primeiro corte, pôde-se verificar que o uso do Entec proporcionou teores de proteína bruta maiores, diferindo apenas da uréia. No segundo corte, as fontes nitrogenadas não diferiram entre si. Quando realizou-se o terceiro corte, o sulfato de amônio apresentou o menor teor de proteína bruta, diferindo estatisticamente das fontes Entec e Uréia.

Com relação à interação entre doses de nitrogênio e cortes observa-se que os teores de proteína bruta foram influenciados pelo aumento das doses de nitrogênio (Figura 3). À medida que se aumentaram as doses de nitrogênio, ocorreu aumento considerável no teor médio de proteína bruta, para o primeiro e terceiro cortes. As médias dos teores de proteína bruta variaram de $10,65 \%$, para o tratamento testemunha, a $17,67 \%$, na maior dose de nitrogênio aplicada.

No primeiro corte, observou-se comportamento linear crescente, enquanto que, no segundo corte, não houve efeito significativo, pois ocorreu oscilação nos teores de proteína bruta. Essa oscilação pode ter sido ocasionada pelas condições pluviométricas no período em que se realizou o segundo corte (Figura 1). No terceiro corte, pôde-se verificar regressão quadrática com o ponto de máxima estimado superior a $200 \mathrm{~kg} /$ ha de $\mathrm{N}$ (cerca de 19\% de PB). Tais resultados são semelhantes aos encontrados por Menegatti et al. (2002) em gramíneas do gênero Cynodon e inferiores aos de Cecato et al. (2004) em capim Brachiaria brizantha, no período de inverno e verão. Segundo Soest (1994), com os teores de PB das forrageiras inferiores a 7\% ocorre redução na digestão da mesma devido a inadequados níveis de nitrogênio para os microorganismos do rúmen, diminuindo sua população e, conseqüentemente, redução da digestibilidade e da ingestão da massa seca. Assim, um teor mais alto de PB é necessário para o atendimento das exigências protéicas do organismo animal. Neste trabalho, pôdese observar que os teores de PB estiveram acima de $9 \%$. 


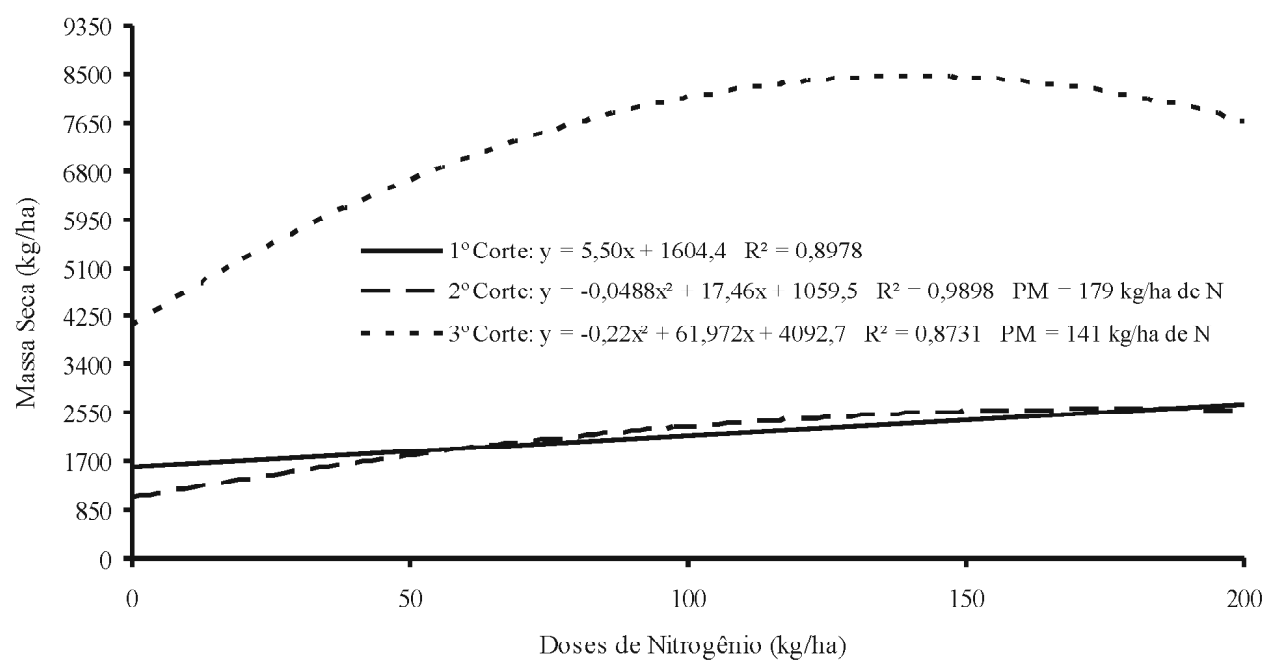

Figura 2 - Produtividade de massa seca (kg/ha) em função das doses de nitrogênio e cortes no capim Bachiaria brizantha cv. Marandu, referentes a três cortes. Ilha Solteira-SP, 2007.

Tabela 1 - Teores de proteína bruta (\% PB) em função de cortes e fontes nitrogenadas no capim Bachiaria brizantha cv. Marandu, referentes a três cortes. Ilha Solteira-SP, 2007.

\begin{tabular}{lccc}
\hline \multirow{2}{*}{ Fontes } & \multicolumn{3}{c}{ Cortes } \\
\cline { 2 - 4 } & $1^{\text {o }}$ & $2^{\text {o }}$ & $3^{\circ}$ \\
\hline Entec & $14,86 \mathrm{~A}$ & $15,37 \mathrm{~A}$ & $16,19 \mathrm{~A}$ \\
Uréia & $11,56 \mathrm{~B}$ & $15,36 \mathrm{~A}$ & $16,08 \mathrm{~A}$ \\
Sulfato de Amônio & $13,68 \mathrm{AB}$ & $14,87 \mathrm{~A}$ & $12,94 \mathrm{~B}$ \\
\hline
\end{tabular}

Obs.: Médias seguidas por mesma letra maiúscula, nas colunas, não diferem entre si, ao nível de $5 \%$ de probabilidade, pelo teste Tukey.

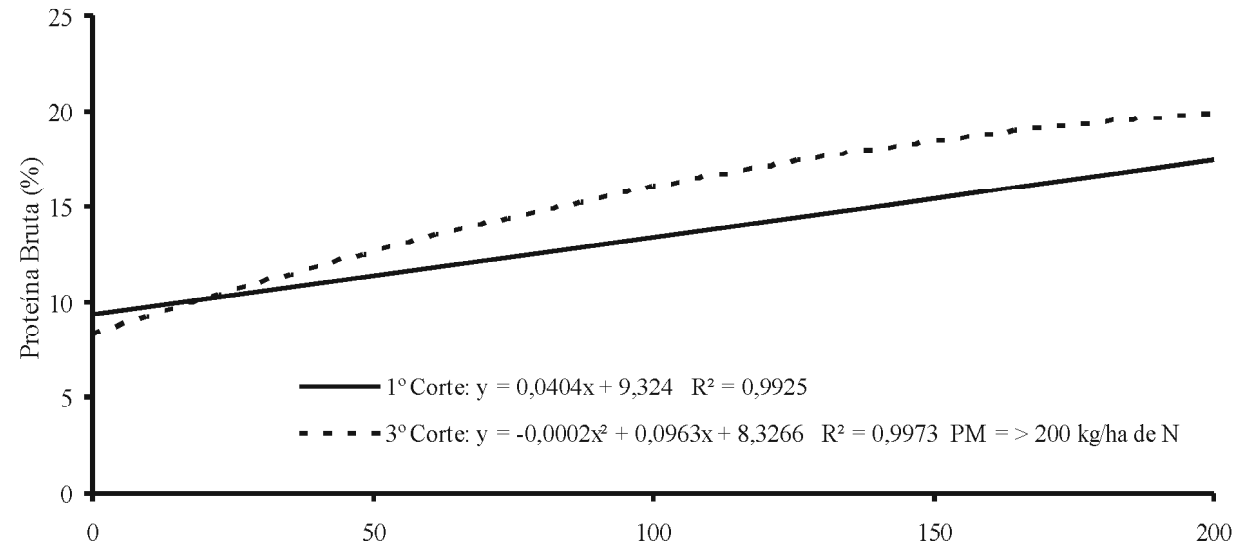

Doses de Nitrogênio (kg/ha)

Figura 3 - Teores de proteína bruta (\% MS) em função de doses de nitrogênio e cortes no capim Bachiaria brizantha cv. Marandu, referentes a três cortes. Ilha Solteira-SP, 2007. 
O teor de fibra em detergente neutro (FDN) e nutrientes digestíveis totais revelaram efeito significativo para corte e para doses de nitrogênio. Quando se analisou o efeito da época de corte para os teores de FDN (Tabela 2), observouse que, no terceiro corte, os teores foram superiores aos demais. Resultados semelhantes foram encontrados por Dias et al. (2000), ao realizarem adubação nitrogenada em forrageiras tropicais. Os valores do terceiro corte podem ser devido à maior produtividade de massa seca.

Quando se analisou o efeito da época de corte nos teores de NDT (Tabela 2), observou-se que o terceiro corte foi inferior aos demais.

Tabela 2 - Teores médios de fibra em detergente neutro e nutrientes digestíveis totais (\% MS) em função de cortes no capim Bachiaria brizantha cv. Marandu, referentes a três cortes. Ilha Solteira-SP, 2007.

\begin{tabular}{|c|c|c|}
\hline \multirow{2}{*}{ Cortes } & \multicolumn{2}{|c|}{ Médias } \\
\hline & FDN & NDT* \\
\hline $1^{\circ}$ & 65,63 B & $56,41 \mathrm{~A}$ \\
\hline $2^{o}$ & 65,36 B & $56,37 \mathrm{~A}$ \\
\hline $3^{\circ}$ & $70,45 \mathrm{~A}$ & $54,41 \quad$ B \\
\hline
\end{tabular}

Tukey. * Estimado de acordo com a equação descrita por Cappelle et al. (2001).

Quando se analisaram os teores de FDN para doses de nitrogênio (Figura 4), constatou-se comportamento linear negativo de acordo com as doses crescentes de nitrogênio aplicadas ao solo. Esses resultados são semelhantes aos obtidos por Cecato et al. (2004) que utilizaram diferentes doses de nitrogênio (0, 200, 400 e 600 $\mathrm{kg} / \mathrm{ha}$ ), no capim Brachiaria brizantha.

De acordo com os resultados encontrados por Dias et al. (2000), doses mais elevadas de nitrogênio aplicadas em determinada época, dependendo das condições ambientais, podem alterar o teor de FDN das forrageiras. Gerdes et al. (1999) observaram que o capim-Marandu, aos 35 dias de crescimento após o corte de uniformização, proporcionou teores de $11,4 \%$ e $72,7 \%$, respectivamente para PB e FDN, quando utilizaram adubação nitrogenada e potássica de $40 \mathrm{~kg} / \mathrm{ha}$ de $\mathrm{N}$ e $30 \mathrm{~kg} / \mathrm{ha}$ de $\mathrm{K}_{2} \mathrm{O}$. Soest (1994) relatou que o teor de FDN é o fator mais limitante do consumo de volumosos, sendo que teores dos constituintes da parede celular superiores a 55-60\%, na massa seca, correlacionam-se de forma negativa com o consumo de forragem. Sendo assim, a concentração de FDN é o componente da forragem mais consistentemente associada ao consumo.
De acordo com os dados referentes às doses de nitrogênio, constatou-se que os teores de nutrientes digestíveis totais foram influenciados por tais doses (Figura 4).

À medida que se aumentaram as doses de nitrogênio ocorreu aumento considerável nos teores médios de nutrientes digestíveis totais, do primeiro ao terceiro corte. As médias dos teores variaram de 54,63\% para o tratamento testemunha a $56,72 \%$, na maior dose de nitrogênio aplicada. Segundo Soest (1994), os teores de NDT das forrageiras são de , aproximadamente, 55\%, podendo ser alterados de acordo com as condições climáticas, o solo e a idade de corte das plantas. Esses resultados foram semelhantes aos obtidos por Agulhon et al. (2004), quando trabalharam com o capim Brachiaria brizantha cv. Marandu, em diferentes períodos de corte.

Os teores de fibra em detergente ácido (FDA) apresentaram interação significativa para doses de nitrogênio e corte (Figura 5). As plantas foram influenciadas pelas doses crescentes de nitrogênio aplicadas ao solo, mostrando comportamento linear negativo, para o primeiro e segundo cortes. Já para o terceiro corte, não houve efeito significativo. Esse fato pode ser explicado devido ao alto índice pluviométrico que ocorreu no período em que se realizou tal corte, havendo aumento na produtividade de massa seca e proteína bruta.

Os teores médios de fibra em detergente ácido determinados foram de $34,06 \%$. Esses resultados foram superiores aos obtidos por Rocha et al. (2001) quando trabalharam com gramíneas do gênero Cynodon e semelhantes aos encontrados por Magalhães et al. (2005), trabalhando com doses crescentes de nitrogênio $(0,100$, 200 e $300 \mathrm{~kg} / \mathrm{ha} / \mathrm{ano}$ ) e fósforo (0, 50 e $100 \mathrm{~kg} / \mathrm{ha} / \mathrm{ano})$, no capim Brachiaria decumbens. Também, Gargantini (2005), ao trabalhar com doses de nitrogênio $(0,25,50$ e $100 \mathrm{~kg} / \mathrm{ha} /$ corte) no capim-Mombaça verificou decréscimos nos teores de FDA com aumento nas doses de N. Segundo Nussio et al. (1998), forragens com valores de FDA em torno de $40 \%$, ou mais, apresentam baixo consumo e menor digestibilidade.

Os teores médios de clorofila, medidos em unidade SPAD, revelaram efeito significativo para cortes e com interação para doses versus fontes de nitrogênio. Em relação aos cortes, constatou-se que o segundo corte proporcionou leituras SPAD superiores $(39,27)$, em relação ao primeiro corte $(36,68)$ e ao terceiro corte $(35,18)$ (Tabela 4). 


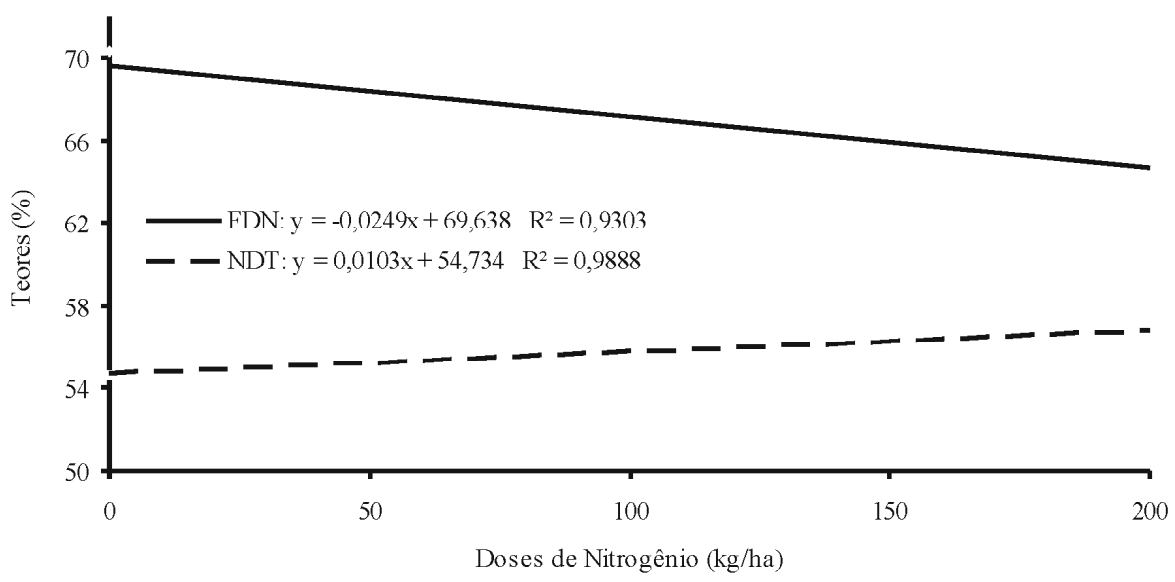

Figura 4 - Teores de fibra em detergente neutro e nutrientes digestíveis totais (\% MS) em função de doses de nitrogênio no capim Bachiaria brizantha cv. Marandu, referentes a três cortes. Ilha Solteira-SP, 2007.

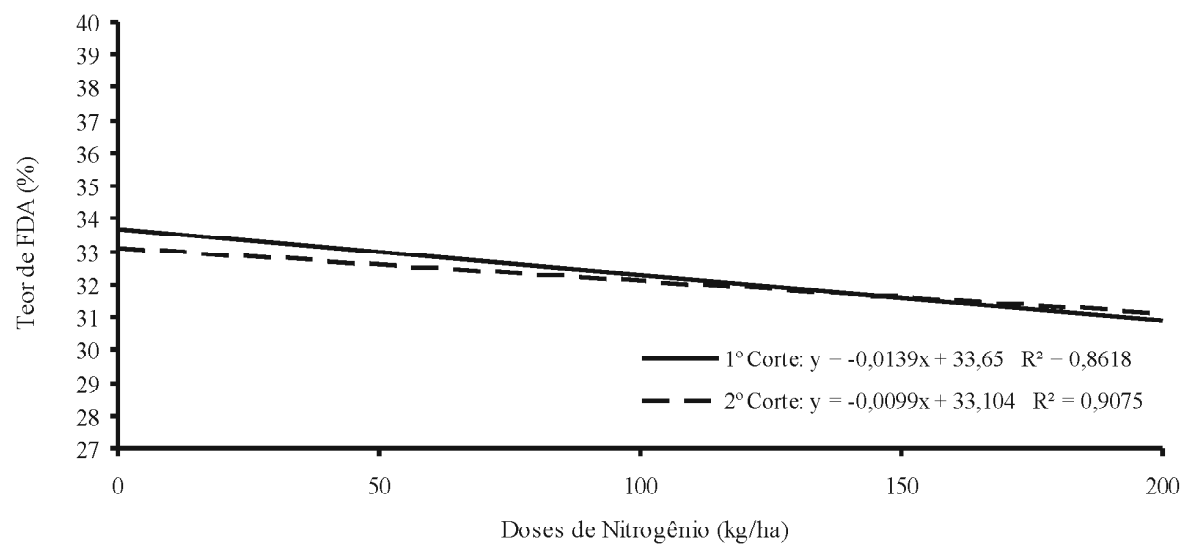

Figura 5 - Teores de fibra em detergente ácido (\% MS) em função de doses de nitrogênio e cortes no capim Bachiaria brizantha cv. Marandu, referentes a três cortes. Ilha Solteira-SP, 2007.

Tabela 4 - Teores médios de clorofia (SPAD) em função dos cortes em Brachiaria brizantha cv. Marandu. Ilha Solteira-SP, 2007.

\begin{tabular}{cl}
\hline Cortes & Médias \\
\hline $1^{\mathbf{o}}$ & $36,68 \mathrm{~B}$ \\
$2^{\mathbf{o}}$ & $39,27 \mathrm{~A}$ \\
$3^{\mathrm{o}}$ & $35,18 \mathrm{~B}$ \\
\hline
\end{tabular}

Obs.: Médias seguidas por mesma letra maiúscula, nas colunas, não diferem entre si, ao nível de 5\% de probabilidade, pelo teste de Tukey.

As fontes utilizadas influenciaram significativamente o teor de clorofila (SPAD). Houve oscilação nos teores, de acordo com as doses de nitrogênio, utilizadas (Figura 6). Quando se utilizou o
Entec e a Uréia como fonte de nitrogênio houve aumento linear nos teores de clorofila. Os resultados obtidos foram semelhantes aos encontrados por Bonfim-da-Silva (2005) e Mattos (2001), que constataram aumento no teor de clorofila, em função da quantidade de nitrogênio aplicada. Para a fonte sulfato de amônio, os dados se ajustaram a uma regressão quadrática, com o ponto de máxima estimado em $174 \mathrm{~kg} / \mathrm{ha}$ de $\mathrm{N}$. Quando se relacionaram os teores de clorofila com os teores de $\mathrm{N}$ na planta, verificaram-se correlações lineares estreitas da ordem de 0,97; 0,94 e 0,96, respectivamente, com as fontes Entec, Sulfato de amônio e Uréia. Isso demonstra que tais leituras podem simular os teores de $\mathrm{N}$ na planta, dando subsídios à aplicação do elemento nos programas de adubação. 


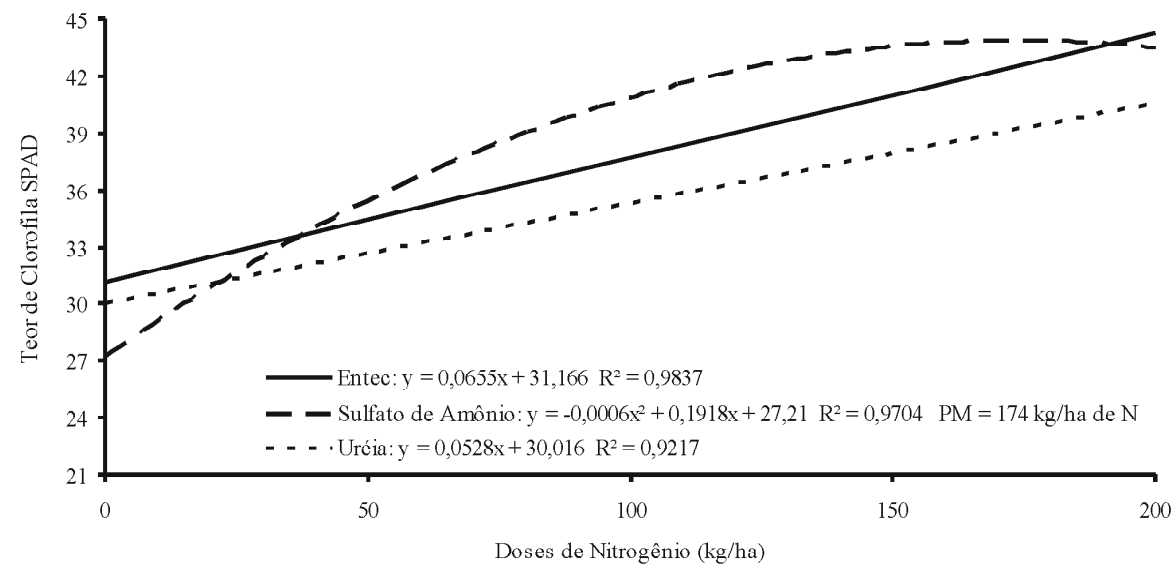

Figura 6 - Estimativa do teor de clorofila em unidades SPAD, em função das doses e fontes de nitrogênio em Bachiaria brizantha cv. Marandu. Ilha Solteira-SP, 2007.

\section{CONCLUSÕES}

Independente da fonte nitrogenada, a aplicação de doses crescentes de até $200 \mathrm{~kg} / \mathrm{ha} /$ corte de $\mathrm{N}$ na forrageira Brachiaria brizantha cv. Marandu proporcionou incremento na produção de massa seca, melhorando a composição bromatológica por aumentar os teores de proteína bruta e nutrientes digestíveis totais e diminuindo os teores de fibras em detergente neutro e fibras em detergente ácido. As leituras em clorofilômetro podem simular o teor de $\mathrm{N}$ na planta.

\section{REFERÊNCIAS BIBLIOGRÁFICAS}

AGULHON, R. A.; JOBIM, C. C.; BRANCO, A. F. Valor nutritivo da massa de forragem ofertada em uma pastagem de capim-Marandu (Urochloa brizantha (Hochst. ex A. Rich.) Webster var Marandu) sob pastejo no inverno. Acta Scientiarum, Maringá, v. 26, n. 2, p. 265-272, 2004.

ALEXANDRINO, E.; NASCIMENTO JUNIOR, D.; REGAZZI, A. J.; MOSQUIM, P. R.; ROCHA, F. C.; SOUZA, D. Características morfogênicas e estruturais da Brachiaria brizantha cv. Marandu submetida a diferentes doses de nitrogênio e freqüências de cortes. Acta Scientiarum, Maringá, v. 27, n. 1, p. 7-14, 2005.

BONFIM-DA-SILVA, E. M. Nitrogênio e enxofre na recuperação de pastagem de capim Brachiaria em degradação em Neossolo quartzarênico com expressiva matéria orgânica. 2005. 123 f. Tese (Doutorado) - Escola Superior de Agricultura "Luiz de Queiroz", Piracicaba, 2005.
CAPPELLE, E. R.; VALADARES FILHO, S. C.; SILVA, J. F. C. Estimativas do valor energético a partir de características químicas e bromatológicas dos alimentos. Revista Brasileira Zootecnia, Viçosa, v. 30, n. 6, p. 1837-1856, 2001.

CARVALHO, M. M.; MARTINS, C. E.; VERNEQUE, R. S.; SIQUEIRA, C. Resposta de uma espécie de braquiária à fertilização com nitrogênio e potássio em um solo ácido. Revista Brasileira de Ciência do Solo, Campinas, v. 15, n. 2, p. 195-200, 1991.

CECATO, U.; PEREIRA, L. A. F.; JOBIM, C. C. Influência das adubações nitrogenadas e fosfatadas sobre a composição químico-bromatológica do capim-Marandu (Brachiaria brizantha) (Hochst) Stapf cv Marandu). Acta Scientiarum, Maringá, v. 26, n. 3, p. 409-416, 2004.

DIAS, P. F.; ROCHA, G. P.; ROCHA FILHO, R. R. Produção e valor nutritivo de gramíneas forrageiras tropicais, avaliadas no período das águas, sob diferentes doses de nitrogênio. Ciência e Agrotecnologia, Lavras, v. 24, n. 1, p. 260-271, 2000.

DUPAS, E. Doses de nitrogênio com e sem irrigação nos cultivares Mombaça (Panicum maximum Jaq.) e Marandu (Brachiaria brizantha) na região de Ilha Solteira-SP. 2006. 39 f. Graduação (Agronomia) - Universidade Estadual Paulista “Júlio de Mesquista Filho", Ilha Solteira, 2006.

EMPRESA BRASILEIRA DE PESQUISA AGROPECUÁRIA. Sistema brasileiro de classificação de solos. Brasília, DF: Embrapa-CNPS, 1999. 412 p. 
FABRÍCIO, J. A. Produtividade e composição bromatológica do capim-Tobiatã em função da adubação NPK. 2007. 56 f. Dissertação (Mestrado) - Universidade Estadual Paulista "Julio de Mesquita Filho", Ilha Solteira, 2007.

FAGUNDES, J. L.; FONSECA, D. M.; GOMIDE, J. A. Acúmulo de forragem em pastos de Brachiaria decumbens adubados com nitrogênio. Pesquisa Agropecuária Brasileira, Brasília, v. 40, n. 4, p. 397-403, 2005.

GARGANTINI, P. E. Irrigação e adubação nitrogenada em capim-Mombaça (Panicum maximum Jacq.) na região oeste do Estado de São Paulo. 2005. 95 f. Dissertação (Mestrado) - Universidade Estadual Paulista "Julio de Mesquita Filho", Ilha Solteira, 2005.

GERDES, L.; WERNER, J. C.; COLOZZA, M. T. Composição química dos capins Marandu, Setária e Tanzânia em diferentes idades de corte. In: REUNIÃO ANUAL DA SOCIEDADE BRASILEIRA DE ZOOTECNIA, 36., 1999, Porto Alegre. Anais... Porto Alegre: Sociedade Brasileira de Zootecnia, 1999.

MAGALHÃES, A. F.; PIRES, A. J. V.; CARVALHO, G. G. P. Composição bromatológica do capim Brachiaria decumbens Stapf adubado com doses crescentes de nitrogênio e de fósforo. In: REUNIÃO ANUAL DA SOCIEDADE BRASILEIRA DE ZOOTECNIA, 42., 2005, Goiânia. Anais... Goiânia: Sociedade Brasileira de Zootecnia, 2005. CD-ROM.

MATTOS, W. T. Avaliação de pastagem de capim Brachiaria em degradação e sua recuperação com suprimento de nitrogênio e enxofre. 2001. 97 f. Tese (Doutorado) - Escola Superior de Agricultura "Luiz de Queiroz", Piracicaba, 2001.
MENEGATTI, D. P.; ROCHA, G. P.; FURTINI NETO, A. E. Nitrogênio na produção de matéria seca, teor e rendimento de proteína bruta de três gramíneas do gênero Cynodon. Ciência e Agrotecnologia, Lavras, v. 26, n. 3, p. 633-642, 2002.

NUSSIO, L. G.; MANZANO, R. P.; PEDREIRA, C. G. S. Valor alimentício em plantas do gênero Cynodon. In: SIMPÓSIO SOBRE MANEJO DA PASAGEM, 15., 1998, Piracicaba. Anais... Piracicaba: FEALQ/ESALQ, 1998, p. 203-242.

PRIMAVESI, A. C.; PRIMAVESI, O.; CORRÊA, L. A. Nutrientes na fitomassa de capim-Marandu em função de fontes e doses de nitrogênio. Ciência e Agrotecnologia, Lavras, v. 30, n. 3, p. 562-568, 2006.

ROCHA, G. P.; EVANGELISTA, A. R.; PAIVA, P. C. A. Digestibilidade e fração fibrosa de três gramíneas do gênero Cynodon. Ciência e Agrotecnologia, Lavras, v. 25, n. 2, p. 396-407, 2001.

RUGGIERI, A. C.; FAVORETTO, V.; MALHEIROS, E. B. Efeito de níveis de nitrogênio e regimes de corte na distribuição, na composição bromatológica e na digestibilidade in vitro da matéria seca da Brachiaria brizantha (HOCHST) Stapf. Cv. Marandu. Revista Brasileira de Zootecnia, Viçosa, v. 24, n. 1, p. 21-30, 1995.

SILVA, D. J.; QUEIROZ, A. C. Análise de alimentos: métodos químicos e biológicos. 3. ed. Viçosa: UFV, 2002. $235 \mathrm{p}$.

SOEST, P. J. van. Nutritional ecology of the ruminant. 2. ed. New York: Cornell University, 1994. 